\title{
Functional MR imaging exposes differential brain responses to syntax and prosody during auditory sentence comprehension
}

\author{
Martin Meyer ${ }^{\mathrm{a}, \mathrm{b}, *}$, Kai Alter ${ }^{\mathrm{a}}$, Angela Friederici ${ }^{\mathrm{a}}$ \\ ${ }^{a}$ Max Planck Institute of Cognitive Neuroscience, Leipzig, Germany \\ ${ }^{\mathrm{b}}$ Division of Informatics, Centre for Functional Imaging Studies, University of Edinburgh, \\ Forrest Hill, Edinburgh EH1 2QL, UK
}

\begin{abstract}
In two experiments using event-related functional magnetic resonance imaging we studied healthy adults who listened to sentences that either focused on lexical, syntactic, or prosodic information. In the first experiment two sentence conditions were employed: normal speech which contained function and content words, and pseudo speech which contained function and pseudo words. Sentence processing generally activated the superior temporal region (STR) bilaterally. Relative to normal sentences hearing pseudo sentences corresponded to stronger brain responses in the anterior STR (planum polare) and in the fronto-opercular region bilaterally. A second experiment was designed to test whether right hemisphere activation can be explained by processing prosodic aspects of speech, i.e. sentence intonation. In addition to normal and pseudo speech the second study examined degraded speech that neither contained morphosyntactic nor lexical information but only prosodic information, i.e. intonation, amplitude, duration, and spectral tilt. Statistical analyses based on regions of interest found differential activation patterns for frontal and temporal areas in the brain. Relative to sentences, degraded speech produced generally stronger activation in frontal regions. Furthermore, the data pointed to a particular involvement of right fronto-lateral regions in processing sentence melody. For the STR an inverse pattern was found: relative to degraded speech sentence conditions produced stronger activation in anterior, mid, and posterior parts of the left supratemporal plane, particular in the planum polare and planum temporale. In sum, the results show that the left planum polare and the left planum temporale mediate syntactic and semantic processing, whereas right fronto-lateral areas seem to be more sensitive to prosodic cues available in spoken language. (C) 2003 Elsevier Science Ltd. All rights reserved.
\end{abstract}

Keywords: Speech perception; Prosody; Functional magnetic resonance imaging; Planum temporale; Planum polare; Superior temporal region; Frontal operculum

\footnotetext{
* Corresponding author. Address: Division of Informatics, Centre for Functional Imaging Studies, University of Edinburgh, Forest Hill, Edinburgh EH1 2QL, UK. Tel.: + 44-131-650-3086; fax: +44-131-650-6899.

E-mail address: mmeyer@anc.ed.ac.uk (M. Meyer).
} 


\section{Introduction}

Since several neurologists in the 19th century (Paul Broca, Marc Dax, Carl Wernicke) claimed its involvement in language functions, the brain's left hemisphere has been viewed as the language dominant one. Their observations indicated that lesions in anterior and posterior parts of the left peri-sylvian region ${ }^{1}$ caused severe deficits in producing and comprehending speech. To date, most neurological textbooks still favour the traditional view which holds that language functions reside in Broca's and Wernicke's area (Stowe, Haverkort, \& Zwarts, 2003). Originally, Broca's area ${ }^{2}$ was depicted as subserving speech production exclusively whereas Wernicke's area ${ }^{3}$ was assigned to aspects of speech comprehension. However, in the 20th century neurolinguistics has provided evidence that a lesion in Broca's area and the surrounding tissue also affects complex sentence comprehension, in particular syntactic processing (Carramazza \& Zurif, 1976, for a review see Grodzinsky, 2000). Thus, since then Broca's area has been proposed as the seat of syntax in the brain for both speech production and comprehension even though Broca's aphasics have been shown to make use of syntactic knowledge (Linebarger, Schwartz, \& Saffran, 1983).

To date two aspects of the traditional claim have been called into question: the first aspect considers the specificity of Broca's area with respect to syntactic processing. Secondly, the left hemisphere's preponderance for language functions is still a matter of debate since recent neuroimaging studies have shown that speech processing also involves areas in the right hemisphere (Binder et al., 2000; Burton, 2001; Burton, Small, \& Blumstein, 2000; Caplan \& Dapretto, 2001; Hickok \& Pöppel, 2000; Meyer, Friederici, \& von Cramon, 2000; Vouloumanos, Kiehl, Werker, \& Liddle, 2001). With respect to the former aspect, lesion studies investigating patients who display symptoms of agrammatism suggested that Broca's area is the locus of syntactic processing. The widely held belief that Broca's area is specifically associated with syntactic processing has been supported by recent neuroimaging studies (Caplan, Alpert, \& Waters, 1998; 1999; Caplan, Alpert, Waters, \& Olivieri, 2000; Dapretto \& Bookheimer, 1999; Embick, Marantz, Miyashita, O’Neil, \& Sakai, 2000; Inui et al., 1998; Kang, Constable, Gore, \& Avrutin, 1999; Ni et al., 2000). This assertion, however, has been called into question by other recent neuroimaging investigations suggesting that Broca's area is involved in a wide range of cognitive and perceptuomotor functions generally subserving language as well as nonlinguistic processes, for example, the analyses of lexical-semantic information (Poldrack et al., 1999), harmonic sequences (Maess, Kölsch, Gunter, \& Friederici, 2001), slow tonal

\footnotetext{
${ }^{1}$ The peri-sylvian region encompasses the cortical areas along the banks of the Sylvian fissure, namely the posterior part of the inferior frontal gyrus (Broca's area), the entire superior temporal plane including the primary auditory cortex (Heschl's gyrus), and the posterior part of the superior temporal region (planum temporale, planum parietale, Wernicke's area).

2 The term Broca's area refers to the ventral foot of the third frontal convolution lining the ascending branch of the anterior segment of the Sylvian Fissure.

3 The term Wernicke's area refers to the caudal compartment of the superior temporal gyrus including the planum temporale (Bogen \& Bogen, 1976).
} 
frequency glides (Müller, Kleinhans, \& Courchesne, 2001), visually prompted digit sequence learning (Müller, Kleinhans, Pierce, Kemmotsu, \& Courchesne, 2002), perception of the rhythm of motion (Schubotz \& von Cramon, 2001), imagery of motion (Binkofski et al., 2000), and to segmentation processes in speech perception (Burton et al., 2000). Furthermore, a review article on phonological studies by Pöppel provides evidence for an essential contribution of Broca's area to verbal working memory (Pöppel, 1996).

Taken together, these findings are inconsistent with an exclusively syntactic specialization of Broca's area. Moreover, those studies that assessed syntactic functions to Broca's area either confounded syntactic complexity and verbal working memory demands, or syntactic and semantic processing under the same task instructions (Bavelier et al., 1997; Caplan et al., 1998; Dapretto \& Bookheimer, 1999). A recent fMRI study investigating syntactic complexity and working memory demands separately demonstrated that activation in Broca's area reflects syntactic working memory requirements rather than syntactic complexity (Fiebach, Schlesewsky, \& Friederici, 2001). Thus, it seems that the functional role of Broca's area cannot be claimed to be uniquely syntactic.

An additional challenge for the view that the language relevant areas are exclusively located in the left hemisphere comes from studies that investigated sentence-level syntactic processing (Just, Carpenter, Keller, Eddy, \& Thulborn, 1996; Keller, Caplan, \& Waters, 2001; Meyer et al., 2000; Müller et al., 1997; Newman, Pancheva, Ozawa, Neville, \& Ullman, 2001; Sakai, Hashimoto, \& Homae, 2001; Vandenberghe, Nobre, \& Price, 2002). These studies reported bilateral peri-sylvian regions to be involved whenever a resting period or auditory non-speech stimuli served as baselines. A substantial involvement of the right hemisphere was observed whenever sentences were presented auditorily (Mazoyer et al., 1993; Meyer et al., 2000; Müller et al., 1997) suggesting that the comprehension of auditorily presented normal sentences, in particular, recruits bilateral areas in the peri-sylvian region. However, the investigation of normal sentence comprehension (in comparison to such baselines) does not necessarily expose brain areas specifically involved in syntactic computation because in normal sentences syntactic cues are confounded with lexical-semantic information. The present article aims to address some of the aforementioned issues. A first experiment was designed to identify brain areas specifically assigned to syntactic processing. To avoid any confound between the presence of lexical-semantic and syntactic cues we investigated the processing of pseudo speech which consists of grammatically correct sentences in which nouns, adjectives and verbs are replaced by pseudowords. By presenting pseudo speech we expected to activate the neural network subserving syntactic functions to a greater extent, because pseudo speech is thought to emphasize syntactic operations, i.e. building a sentence structure and dealing with morphosyntactic information. The second experiment was performed to identify the particular contribution of the right hemisphere in speech comprehension. To achieve this goal we constructed stimulus material which was free of lexical-semantic and syntactic information but preserved the prosodic cues (intonation contour) of normal sentences. 


\subsection{Experiment 1: syntax in focus}

In this experiment, we compared (semantically) normal sentences and (semantically meaningless) pseudo sentences within one experimental paradigm. ${ }^{4}$

\subsubsection{Materials and methods}

Stimuli and design. All sentences were recorded by a trained female speaker in a soundproof room (IAC) and digitized at a $16 \mathrm{bit} / 41.1 \mathrm{kHz}$ sampling rate. The mean length of the sentences in the normal speech condition was $3.4 \pm \mathrm{SD} 0.36 \mathrm{~s}$, and in the syntactic speech condition $3.6 \pm$ SD $0.35 \mathrm{~s}$. The mean sound pressure level for the normal speech condition was $20 \mathrm{~dB}$ (SPL) and for the pseudo speech condition $21 \mathrm{~dB}$ (SPL).

Normal speech-Grammatically, semantically and phonologically correct sentences.

Die besorgte Mutter sucht das weinende Kind.

The anxious mother searches for the crying child.

Pseudo speech-Grammatically correct pseudo sentences without semantics. Here, content words were replaced by phonotactically legal pseudowords whereby morphological inflections, determiners and auxiliaries remained unaltered. Syntactic assignments determining the role of the sentence's constituents were therefore still possible even though the meaning of the sentence had been removed.

Das mumpfige Folofel hongert das apoldige Trekon.

The mumpfy folofel hongers the apoldish trekon.

Across the two conditions half the stimuli were active sentences and half were passive sentences. Each condition comprised 36 trials, which were presented in stereo sound in an unpredictable order to enable event-related analysis (D'Esposito, Zarahn, \& Aguirre, 1999; Zarahn, Aguirre, \& D'Esposito, 1997). ${ }^{5}$ Each trial started with a warning tone preceding sentence onset. Each sentence presentation was followed by an Inter-TrialInterval lasting 8-10 s to allow the fMRI signal to decrease adequately. To maintain the subjects' attention while listening to the stimuli, they were requested to judge whether the sentence contained meaningful words by pressing a button after each trial.

\footnotetext{
${ }^{4}$ The experimental paradigm contained two additional (normal and pseudo) word list conditions which are not discussed here. For details see Friederici, Meyer, and von Cramon (2000a).

${ }^{5}$ Previous brain imaging studies often made use of the subtraction paradigm as an appropriate design. Methodologically, this approach is based on a blocked stimulus presentation. In other words, a reasonable number of experimental stimuli that represent one experimental condition are presented block-wise. The use of block paradigms has been shown to combine a number of disadvantages: signal habituation due to the predictable character of the stimuli or loss of subjects' attention. (Friston et al., 1996). One alternative approach to overcome these drawbacks is the event-related design. Similar to behavioural studies, experimental stimuli entailing different experimental conditions are presented in a pseudo-random order. However, given the temporal characteristics of the hemodynamic response, two succeeding stimuli have to be separated by a time interval that usually lasts 5-10 s. Though the signal-to-noise ratio in event-related studies is lower relative to blocked designs, event-related fMRI has been proven to be sufficiently sensitive to transient signal changes elicited by rapidly occurring neuronal events (Rosen, Buckner \& Dale, 1998).
} 
Participants. Eighteen right-handed native speakers of German (7 male, age range 20-26) participated in the study after giving informed written consent in accordance with the guidelines approved by the Ethics Committee of the Leipzig University Medical Faculty. Subjects had no hearing or neurological disorders and normal structural MRI scans. They had no prior experience with the task and were not familiar with the stimulus material.

MR Imaging. MRI data were collected at $3.0 \mathrm{~T}$ using a Bruker 30/100 Medspec system (Bruker Medizintechnik GmbH, Ettlingen, Germany). For each subject, structural and functional (echo-planar) images were obtained from eight axial slices parallel to the plane intersecting the anterior and posterior commissures (AC-PC plane). The slice thickness was $4 \mathrm{~mm}$ with an inter-slice gap of $2 \mathrm{~mm}$ covering the entire peri-sylvian cortex. After defining the slice positioning, conventional T1-weighted anatomical images (IR-RARE sequence: TE $20 \mathrm{~ms}$, TR $3750 \mathrm{~ms}$, in plane-resolution $0.325 \mathrm{~mm}^{2}$ ) were collected in plane with the echo-planar images, to align the functional images to the structural images. A gradient-echo EPI sequence was used with a TE $30 \mathrm{~ms}$, flip angle $90^{\circ}$, TR $2 \mathrm{~s}$, acquisition bandwidth $100 \mathrm{kHz}$. Acquisition of the slices within the TR was arranged so that the slices were all rapidly acquired followed by a period of no acquisition to complete the TR. The matrix acquired was $64 \times 64$ with a FOV of $19.2 \mathrm{~cm}$, resulting in an in-plane resolution of $3 \mathrm{~mm} \times 3 \mathrm{~mm}$. In a separate session high resolution whole-head 3D MDEFT brain scans (128 sagittal slices, $1.5 \mathrm{~mm}$ thickness,) were acquired additionally for reasons of improved localization (cf. Data Analysis) (Norris, 2000; Ugurbil et al., 1993). Participants were provided with headphones designed specifically for use in scanner environment. A combination of external ear defenders and perforated ear plugs was used to attenuate the scanner noise without reducing the quality of binaural stimulation.

Data analysis. For data analysis, software (LIPSIA, BRIAN) developed at the Max Planck Institute of Cognitive Neuroscience was used (Kruggel \& Lohmann, 1996; Lohmann et al., 2001). First, the data were corrected for motion artefacts. Signal changes and baseline-drifts were removed by applying a temporal high-pass filter to remove frequencies lower than $1 / 32 \mathrm{~Hz}$.

Firstly, a rigid linear registration that yielded an individual transformation matrix was calculated to align the functional data slices onto a three-dimensional stereotactic coordinate reference system. Then, each individual transformation matrix was linearly scaled to the standard Talairach brain size (Talairach \& Tournoux, 1988). The resulting parameters were then used to align the $2 \mathrm{D}$ functional slices with the whole-head $3 \mathrm{D}$ MDEFT brain scans.

Prior to multi-subject averaging, functional activation within each individual dataset was calculated for each condition separately. Changes in local blood supply were detected by computing a pixel-wise Pearson correlation of the MR signal and a 4-s delayed box car reference wave form. The correlation coefficient for each single voxel was transformed to $Z$-values (via Fisher's $Z$-transformation). Individual activation maps were calculated without thresholding $(z \geq 0, p=1)$. Normalized $Z$-maps were averaged by computing pixel-wise averages of individual input images. Each voxel in the output image contained the average $Z$-value of the corresponding voxels in the input image. The $Z$-map average was multiplied by a $Z$-map correction factor of the square root of the current number of 
subjects $(n=18)$ (Bosch, 2000). The statistical analysis was conducted as proposed in Bosch (2000). Four spherical regions of interest (ROIs) were defined in each hemisphere, namely in the deep frontal operculum, in the inferior precentral sulcus, in the anterior STR (planum polare), and in the posterior STR (planum temporale). These particular ROIs were selected under the constraint that a significant activation $(Z>3.09)$ was identified in one of the two conditions. In all cases the spherical ROI contained the local maxim of the summed activation of all conditions. In a second step, normalized $Z$-values were averaged within each ROI, separately for each condition and each participant, allowing the calculation of ANOVAs. All results reported for both Experiments 1 and 2 were significant corresponding to an $\alpha$ of.05 ( $P<10^{-3}$, one tailed).

\subsubsection{Results}

Performance data. The judgment performance revealed approximately perfect correctness of $96.61 \%$ ( $\mathrm{SE}=1.26$ ) for the normal speech, and $89.58 \%$ ( $\mathrm{SE}=4.94$ ) for the pseudo speech condition.

fMRI Data. For sentence processing, strong brain activation was observed in superior temporal regions (STR) for both normal and pseudo speech (see Fig. 1A and $\mathrm{B}$ ).

This activation included the anterior STR (planum polare), the middle STR (Heschl's gyrus), ${ }^{6}$ and the posterior STR (planum temporale) in both the left and the right hemisphere. In all temporal ROIs hemodynamic responses to pseudo speech were significantly stronger than for normal speech. Additionally, both sentence conditions produced stronger activation in the left rather than the right supratemporal plane. $^{7}$

With respect to the frontal cortex, data analyses revealed no notable brain responses to normal speech. Interestingly, pseudo speech evoked a salient signal increase in the deep frontal operculum bilaterally. This region is buried in the frontoopercular cortex directly adjacent to the anterior insula. Although the deep frontal operculum is in the vicinity of the more laterally situated Broca's area, it can clearly be distinguished from it. Notably, the entire fronto-opercular region (FOR) has formerly been considered to be involved in operating speech (Dronkers, Shapiro, Redfern, \& Knight, 1992; Mohr et al., 1978). ${ }^{8}$ In addition to cortical regions, processing both normal and pseudo speech involved subcortical (thalamic) structures bilaterally.

\footnotetext{
${ }^{6}$ Cytoarchitectonic studies demonstrate that the primary auditory cortex usually covers the most medially situated two-thirds of Heschl's gyrus (Morosan et al., 2001).

7 A $(2 \times 2 \times 3)$ ANOVA with factors hemisphere $\times$ ROI $\times$ condition for normal and pseudo speech revealed a main effect of hemisphere $\left(F_{1,17}=13.97, P<.005\right)$, a main effect of condition $\left(F_{1,17}=18.48\right.$, $P<.0005)$, and no significant interaction of hemisphere $\times$ condition $\left(F_{1,17}=2.42\right)$.

${ }^{8}$ Statistical analyses revealed that fronto-opercular activation did not differ between active and passive mode sentences $(F<1)$. This result provides evidence against the Trace Deletion Hypothesis proposed by Grodzinsky (2000) which predicts that the fronto-opercular cortex subserves the processing of passive but not active mode sentences. For detailed discussion see Levelt (2000).
} 


\section{A}

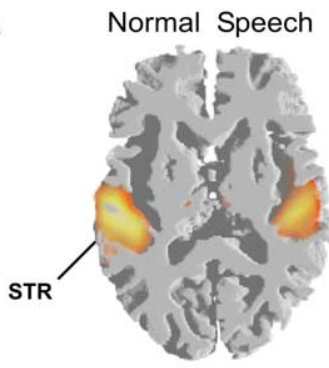

Pseudo Speech
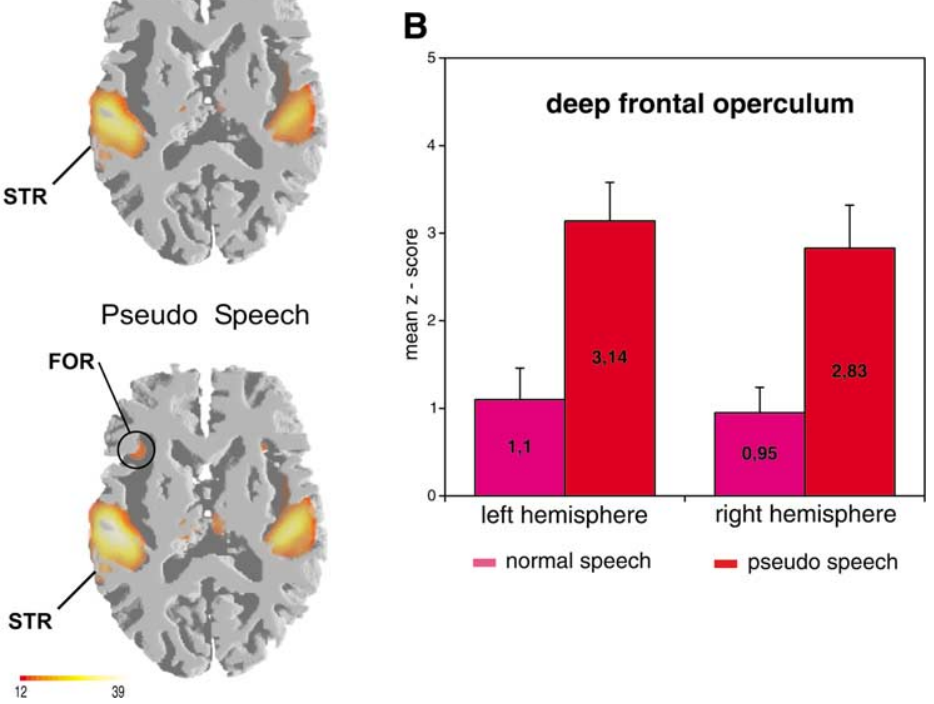

Fig. 1. (A) Inter-subject averaging $(N=18)$ reveals significant hemodynamic responses to normal and pseudo speech in the superior temporal region (STR) bilaterally. The fronto-opercular region (FOR) is only activated by pseudo speech. Here, a horizontal view of functional brain activation intersecting the peri-sylvian cortex is plotted in neurological convention $(Z$-axis $=11)$. All figures display significant brain responses superimposed onto a white-matter segmented 3D reference brain. Thus, the brain's white matter is separated from grey matter so that the cortical layers (the outermost 3-5 mm) are removed. (B) Mean Z-values obtained from the left and right frontal operculum illustrate that this particular brain region is clearly involved in processing pseudo speech lacking lexical information. Listening to normal speech, in contrast, does not significantly activate the deep frontal operculum. The error bars refer to the standard error.

\subsubsection{Discussion}

The results suggest that the cerebral network subserving auditory sentence comprehension involves temporal areas predominantly in the left, but also in the right hemisphere. Consistent with recent claims (Humphries, Buchsbaum, \& Hickok, 2001; Mazoyer et al., 1993; Meyer et al., 2000; Müller et al., 1997; Schlosser, Aoyagi, Fulbright, Gore, \& McCarthy, 1998; Stowe et al., 1998), sentences produced a large region of activation in STRs bilaterally with the anterior part (planum polare) playing a special role. This finding suggests that the anterior temporal cortex is essentially involved in sentencelevel comprehension. Further evidence supporting this view is provided by previous lesion studies (Caplan, Hildebrandt, \& Makris, 1996; Dronkers, Redfern, \& Knight, 1999; Dronkers, Wilkins, Van Vilin, Redfern, \& Jaeger, 1994; Zaidel, Zaidel, Oxbury, \& Oxbury, 1995). These studies demonstrate that brain damage to the left anterior STR causes severe deficits in sentence processing. As a whole these data support the notion that comprehension of simple sentences is instantiated by the temporal rather than the frontal lobes. This finding is in line with a neurocognitive model of auditory sentence 
comprehension (Friederici, 2002) that proposes the left anterior lobe is particularly sensitive to syntactic processing. Further evidence corroborating the view that syntactic processing involves the anterior portion of the STR in particular comes from a study using magnetencephalography (MEG), which delivered participants with syntactically correct and incorrect sentences (Friederici, Wang, Herrman, Maess, \& Oertel, 2000b). Interestingly, brain activation in the superior temporal lobes for pseudo speech was stronger than for normal speech. In a recent review article by Stowe and colleagues it was argued that the left anterior lobe subserves the encoding of some aspects of lexical information that indirectly support sentence processing rather than syntactic processing per se (Stowe et al., 2003). This argument would suggest that identifying pseudo sentences is more difficult because pseudowords are not represented in the mental lexicon (Mazoyer et al., 1993; Price, Wise, \& Frackowiak, 1996; Vandenberghe et al., 2002). Therefore this increase in brain activation might reflect the unsuccessful attempt to process pseudowords, and it is highly likely that this increased processing difficulty corresponds to a slight (but not significant) increase in error rates.

Regarding frontal involvement, data analyses exposed bilateral responses in the deep frontal operculum to pseudo speech but did not reveal any activity for normal speech, neither in the deep frontal operculum nor in the fronto-lateral Broca's area. However, other neuroimaging studies have emphasized the role of Broca's area in sentence comprehension and seem to confirm the traditional view (Bavelier et al., 1997; Caplan et al., 1998; 1999; Dapretto \& Bookheimer, 1999; Embick et al., 2000; Stromswold, Caplan, Alpert, \& Rauch, 1996). These studies report increased local blood supply to Broca's area when syntactically complex sentences are investigated, when verbal working memory was involved, or when visual presentation was utilized. In the study of Dapretto and Bookheimer (1999) the results can also be explained by verbal working memory demands required by the task. Evidence that activation in Broca's area varies as a function of processing effort rather than simple syntactic operations was also recently provided by an fMRI study on written sentence processing that systematically investigated syntactic complexity and short-term memory demands (Cooke et al., 2002). Another recent fMRI study compared auditory to written sentence processing (Carpentier et al., 2001). Only written sentence processing activated Broca's area which led the authors to conclude that Broca's area performs an articulatory recoding of written language. Evidence pointing to the specific involvement of a left frontal region in syntactic processing was recently provided by a PET-study that presented subjects with pseudo sentences (Indefrey, Hagoort, Herzog, Seitz, \& Brown, 2001). However, this syntactic activation was located superior to the inferior frontal sulcus and not in Broca's area. Interestingly, in the present study only syntactically correct but unusual sounding pseudo speech produced significant left (and right) frontal activity. This activation was not found in the lateral convexity of Broca's area. In fact it can be localized bilaterally in the deep frontal operculum lining the anterior insula (cf. Fig. 1A and B). This can be taken as evidence that the deep frontal operculum is not involved in syntactic processing per se. To process unusual language input the brain has to allocate more effort in extracting relevant information from the speech segments. Presumably, the fronto-opercular brain responses to deviant pseudo speech reflect the interaction between speech comprehension and related effort (Giraud 
et al., 2001). Given this data, however, it is not clear whether this process can be considered as linguistic or non-linguistic.

The finding that right cortical areas are also engaged in speech comprehension challenges the traditional notion that auditory language processing is an exclusively lefthemisphere function (Corina, Vaid, \& Bellugi, 1992; Goodglass, 1993). This finding is in harmony with recent work on cortical processing of speech emphasizing that speech perception is mediated bilaterally in superior temporal cortex (Hickok \& Pöppel, 2000). Further evidence comes from the neurocognitive model on auditory sentence processing proposed by Friederici (2002) and the neurobiological model of speech perception proposed by Pöppel (2003). From both models it follows that speech perception is generally mediated by both the left and right hemisphere. Pöppel's model further holds that language processing beyond the analysis of the input signal is lateralized. The present data support this view because sentences produced stronger activation in the left rather than the right hemisphere. According to both models prosodic processing is supposed to involve right hemisphere areas. The right hemisphere's responsiveness to prosodic information was tested in the second experiment.

\subsection{Experiment 2: prosody in focus}

Experiment 2 set out to investigate in how far the right hemisphere may contribute to sentence comprehension. Recent neuroimaging studies provided evidence that the right hemisphere is involved in various non-automatic language functions, i.e. processing metaphors (Bottini et al., 1994), making sense during conversation (Caplan \& Dapretto, 2001), mental repair of incorrect sentences (Meyer et al., 2000), and discourse processing (St. George, Kutas, Martinez, \& Sereno, 1999). According to previous behavioural and lesion studies, however, the right hemisphere seems also to process and produce prosody, i.e. intonation (Behrens, 1989; Brådvik et al., 1991; Bryan, 1989; Heilman, Bowers, Speedie, \& Coslett, 1984; Schirmer, Alter, Kotz, \& Friederici, 2001; Weintraub \& Mesulam, 1981). Prosody is an aspect of the linguistic system and it describes abstract phonological phenomena such as word stress, sentence accent, and phrasing, which relate indirectly to the morphosyntactic structures of utterances (Shattuck-Hufnagel, \& Turk, 1996). The term prosody is also used to refer to the phonetic attributes used to encode these abstract structures, i.e. intonation, amplitude, and duration. Listeners can therefore use intonation, durational, and amplitude information to help decode the syntactic and focus structure of the sentences to which they attend. Perkins and colleagues investigated the prosodic competences of right (RHD) and left (LHD) hemisphere damaged patients who were asked to identify intonation contours as questions or statements in semantically neutral and segmentally degraded sentences ${ }^{9}$ (Perkins, Baran, \& Gandour, 1996). Compared to a normal control group, the LHD patients performed worse in processing intonation contours which were taken from real sentences and serve linguistic function. When the lexical and grammatical information was degraded by low-pass filtering and subjects were required to discriminate between isolated prosodic structures, the RHD

\footnotetext{
${ }^{9}$ Removing spectral frequencies from a speech signal by means of filter procedures yields a degraded speech signal. Details are described in Section 1.2.1.
} 
group demonstrated a significantly poorer performance than the control group. That is, when the linguistic relevance of speech was reduced, the right hemisphere's involvement in prosody comprehension increased. On the basis of these results Perkins and colleagues proposed that a right hemisphere dysfunction caused prosodic-melodic defects, including the impaired processing of speech melody. Further evidence demonstrating an essential role of the $\mathrm{RH}$ in prosodic processing was provided by a dichotic listening study presenting subjects with normal and low-pass filtered sentences (Blumstein \& Cooper, 1974).

Furthermore, from a recent model on cerebral lateralization of speech, it follows that (i) there is a strong bilateral sensitivity to speech perception and (ii) that the right superior temporal lobes support the processing of slowly changing spectral information, namely intonation contour in spoken utterances (Pöppel, 2003). Taking this data together, it is plausible that the right hemisphere activation observed in Experiment 1 can predominantly be attributed to prosody.

The present experiment utilized fMRI to investigate speech melody perception. Three sentence conditions varying with respect to the absence and presence of lexical and morphosyntactic information were designed. As in Experiment 1, volunteers heard normal and pseudo speech. In the third condition-degraded speech-all lexical and morphosyntactic information was filtered out. This filtering procedure yielded a speech signal that was reduced to the acoustic substrates representing prosodic contour. ${ }^{10}$ In other words, listening to degraded speech does not provide information about word forms or morphosyntactic information, but only speech melody cues.

Generally, by presenting degraded speech we were able to test which cerebral hemisphere is more sensitive to acoustic features underlying intonation contour. As outlined above, there is strong evidence pointing to a right hemisphere superiority in processing prosodic cues at the sentence level. Accordingly, the right perisylvian cortex ought to be more involved while subjects listen to degraded speech as compared to normal or pseudo speech. Additionally, relative to normal and pseudo speech, brain responses to degraded speech should be reduced in the STR, in particular in the left hemisphere as these regions are known to accommodate lexical and morphosyntactic processing (Friederici, 2002; Stowe et al., 2003).

\subsubsection{Materials and methods}

Stimuli and design. To generate degraded speech, normal speech files were treated by applying the PURR-filtering procedure (Sonntag \& Portele, 1998). The segmental content, i.e. the spectral qualities of the speech signal were completely removed from the signal. In more detail, pitch marks were extracted from the original signal and then dynamically lowpass filtered with a cut-off frequency up to the third harmonic. The cut-off frequency of the unvoiced segments, i.e. of the aperiodical parts of the signal, were set to zero. The pitch

\footnotetext{
${ }^{10}$ During speech processing the phonetic form of an incoming signal has to be decoded before the relation between phonological and syntactic/semantic properties can be established. Acoustic form detection requires the extraction of the acoustic features relevant for language processing from the signal. In terms of degraded speech the relevant acoustic features consist of spectral frequencies $(F 0, H 2, H 3)$, duration, and the gross shape of relative amplitudes.
} 
marks of the second harmonics were filled with a sinus of $1 / 4$ of the amplitude and the third harmonic of 1/16 of the amplitude (Figs. 2 and 3).

The filter did not affect the fundamental frequency and general amplitude envelope. The signal derived from this filtering procedure contained prosodic parameters (pitch contour and amplitude envelope), but lacked syntactic and lexical information. The degraded speech sounded like a human voice rendered unintelligible by listening from behind a door.

The experimental procedure was identical to Experiment 1. Here, fourteen native speakers of German were asked to indicate if they have just heard an active or passive sentence. Due to the presence of morphosyntactic information, normal and pseudo speech can be identified as active or passive mode sentences. As degraded speech does not contain morphosyntactic information we expect the participants to perform at chance-level. A chance-rate performance can be taken as evidence that the morphosyntactic information has been filtered out of degraded speech.

MR imaging. Data acquisition was identical to Experiment 1.
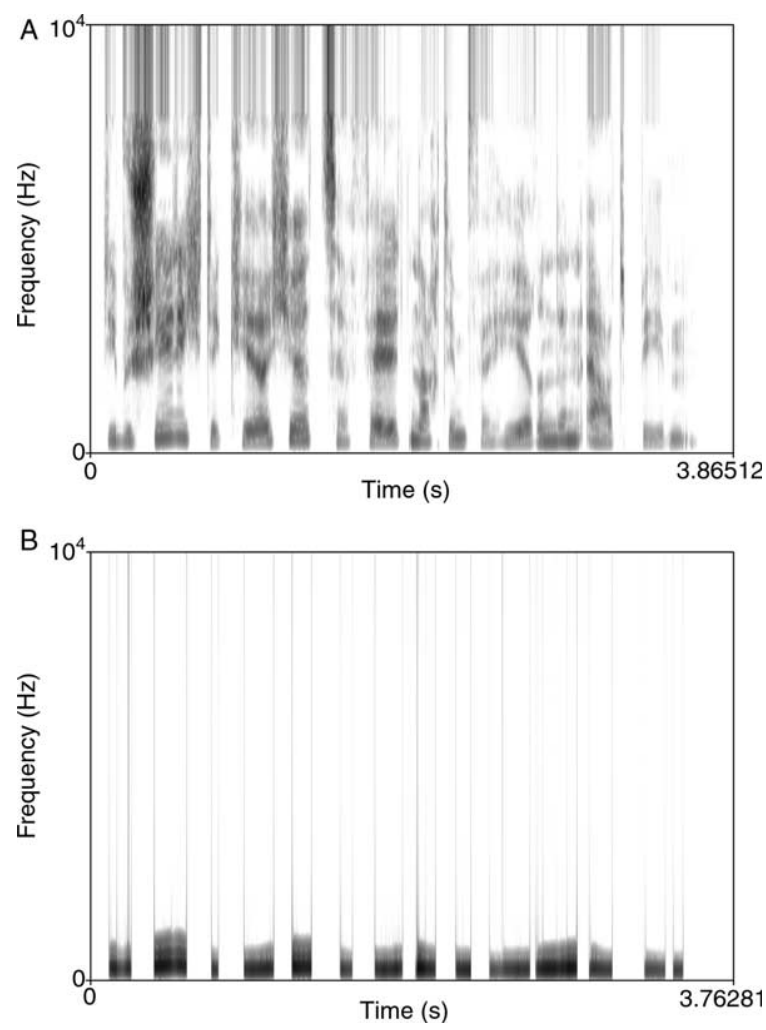

Fig. 2. Wideband spectrogram of speech signal before (A) and after (B) filtering. (A) shows the frequency spectrum for a normal sentence and (B) shows reduced frequency information of a filtered speech signal. 

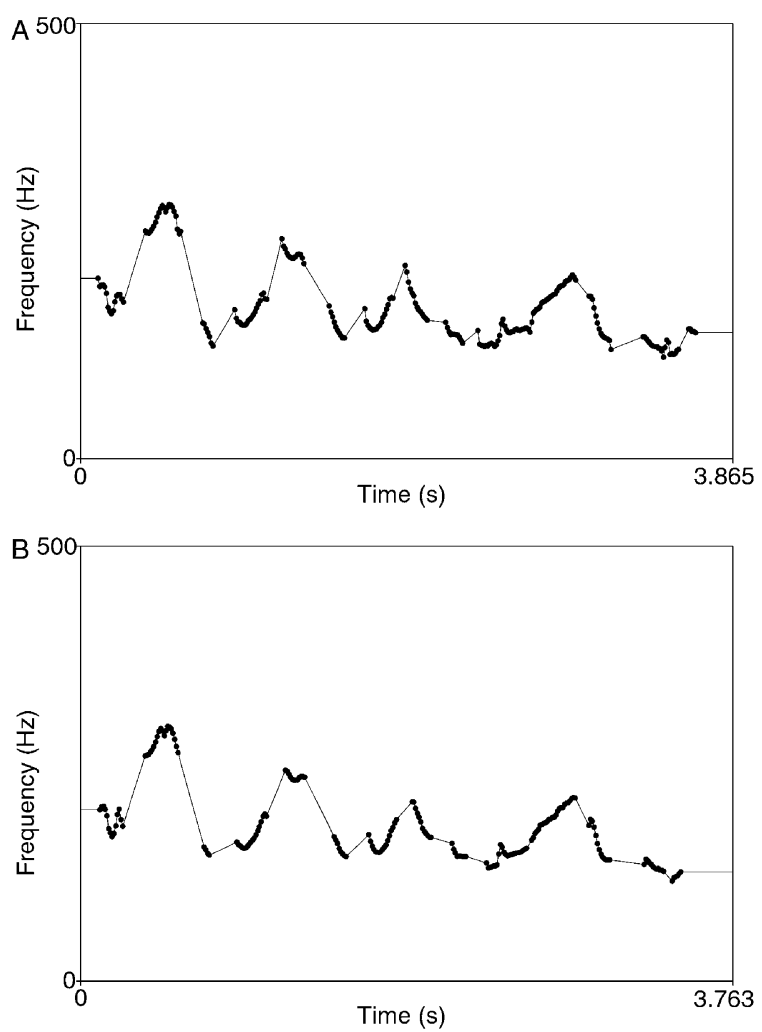

Fig. 3. Pitch tracking of sentence intonation before (A) and after (B) filtering. Filtering speech signals does not affect the dynamic pitch contour of sentences.

Data analysis. Data analysis was identical to Experiment 1 except for the number and position of ROIs. Here, seven post-hoc ROIs were defined in each hemisphere, namely in the deep frontal operculum, in the anterior insula, in the inferior precentral sulcus, in the pars opercularis, in the anterior STR (planum polare), in the middle STR (Heschl's gyrus), and in the posterior STR (planum temporale) (Table 1).

Table 1

Centre of spherical ROIs according to the stereotactic reference system (Talairach \& Tournoux, 1988)

\begin{tabular}{|c|c|c|c|c|c|c|}
\hline \multirow[t]{2}{*}{ Region } & \multicolumn{3}{|l|}{ Left } & \multicolumn{3}{|c|}{ Right } \\
\hline & $X$ & $Y$ & $Z$ & $X$ & $Y$ & $Z$ \\
\hline Pars opercularis & -51 & 7 & 13 & 48 & 10 & 10 \\
\hline Inferior Precentral Sulcus & -47 & 15 & 27 & 41 & 15 & 28 \\
\hline Frontal Operculum & -35 & 13 & 14 & 39 & 13 & 14 \\
\hline Anterior Insula & -31 & 11 & 14 & 27 & 21 & 15 \\
\hline Planum polare & -51 & 2 & 1 & 46 & 2 & 0 \\
\hline Heschl's Gyrus & -48 & -12 & 5 & 47 & -16 & 5 \\
\hline Planum temporale & -50 & -29 & 7 & 51 & -31 & 6 \\
\hline
\end{tabular}




\subsubsection{Results}

Performance data. Passive/active judgment performance was almost perfect for the normal speech $(93.35 \%, \mathrm{SE}=2.77)$ and for the pseudo speech $(91.76 \%, \mathrm{SE}=2.90)$ conditions. Degraded speech produced responses at chance level $(51.78 \%, \mathrm{SE}=1.92)$, clearly demonstrating that pure speech melody cannot be syntactically or lexically decoded.

fMRI data. Analyses of inter-subject averaged responses revealed that hearing normal, pseudo and degraded speech consistently activated cortical segments along the entire peri-sylvian region, namely the inferior frontal and superior temporal lobes bilaterally (Fig. 4).

Generally, all conditions recruited the primary auditory cortex (Heschl's gyrus) as well as surrounding areas of the supratemporal plane, including the anterior (planum polare) and posterior part (planum tempolare). As in Experiment 1, bilateral activation in the STR, including the supratemporal plane as well as the lateral convexity of the superior temporal gyrus, was observed when subjects heard normal sentences. No significant responses were found in the fronto-opercular cortex. Similar to Experiment 1, pseudo speech evoked stronger activity in the STR and in the FOR bilaterally when compared to normal speech. Additionally, pseudo sentences produced stronger activity in the junction area where

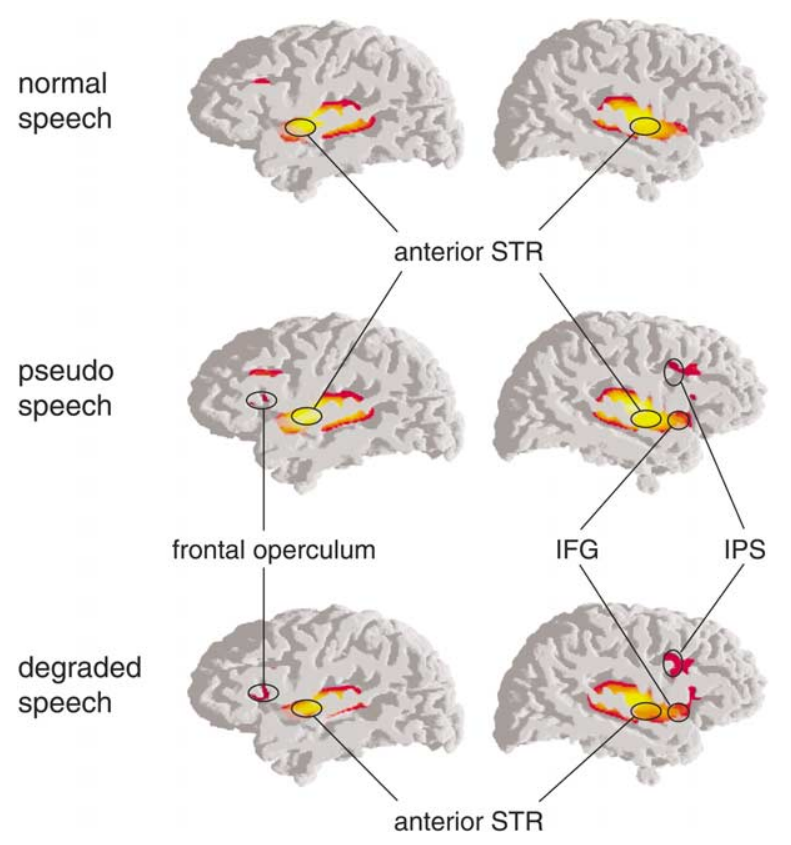

Fig. 4. The figure depicts activation in the left and right peri-sylvian cortex separately for normal, pseudo and degraded speech $(Z>3.09)$. Relative to normal and pseudo speech functional brain responses to degraded speech are reduced in the STR, but increased in right inferior fronto-lateral areas. IFG: inferior frontal gyrus, IPS: inferior precentral sulcus, STR: superior temporal region. 
the left inferior frontal sulcus borders the inferior precentral sulcus and-even more salient—in the right precentral sulcus (IPS).

Degraded speech also involved the STR bilaterally. As predicted, activation in temporal areas bilaterally was reduced when compared to normal and pseudo speech. This held in particular for the left hemisphere. Furthermore, brain responses to degraded speech were stronger in both the left and right fronto-opercular cortex as well as in the right IPS than activation for normal and pseudo speech.

Regions of interest. For the purpose of testing whether these differences in local brain activation are statistically reliable, mean $Z$ scores of seven spherical ROIs were subjected to systematic analyses (ANOVAs). These analyses demonstrated that local brain responses varied considerably as a function of acoustic, linguistic, and prosodic information available in the different speech conditions.

A global $(2 \times 7 \times 3)$ ANOVA with factors hemisphere $\times R O I \times$ condition revealed a main effect of condition, a main effect of $R O I$ and an interaction of ROI $x$ condition, indicating a different pattern of brain responses in distinct ROS (Table 2: Fig. 5). No main effect of hemisphere was found, but two interactions of hemisphere x condition, and of hemisphere $x$ ROI $x$ condition showed that activation varied within hemispheres as a function of different conditions (Table 2).

An $(2 \times 7 \times 2)$ ANOVA with factors hemisphere $\times$ ROI $\times$ condition was also performed only comparing normal and pseudo speech. This comparison revealed a main effect of condition, but no main effect of hemisphere or an interaction hemisphere $\times$ condition (Table 3: Fig. 5).

Like Experiment 1, these data showed that brain activation for pseudo speech was stronger than activation for normal speech. However, no prevalence of either the left or right hemisphere could be concluded. Ergo, the degraded speech condition accounted for the differences in the lateralization of brain activation as apparent from the global ANOVA.

The upper row of Fig. 5 shows that degraded speech involved right frontal areas more than left frontal areas, whereas the lateralization of functional responses was less clear in superior temporal ROIs. To test the different functional laterality for segmental stimuli (sentences) and degraded stimuli (speech melody), mean $Z$-scores of the two sentences

Table 2

Results of a $(2 \times 7 \times 3)$ ANOVA with factors hemisphere $\times$ ROI $\times$ condition for normal, pseudo, and degraded speech

\begin{tabular}{lrrr}
\hline Factor & DF & $F$ value & $P$ value \\
\hline ROI & 6,78 & 31.97 & $P<0.0001$ \\
Hemisphere & 1,13 & 0.03 & $\mathrm{~ns}$ \\
Condition & 2,26 & 25.75 & $P<0.0001$ \\
Hemisphere $\times$ condition & 2,26 & 25.55 & $P<0.0001$ \\
ROI $\times$ hemisphere & 6,78 & 1.18 & $\mathrm{~ns}$ \\
ROI $\times$ condition & 12,156 & 17.00 & $P<0.0001$ \\
ROI $\times$ hemisphere $\times$ condition & 12,156 & 1.81 & $p=0.0507$ \\
\hline
\end{tabular}



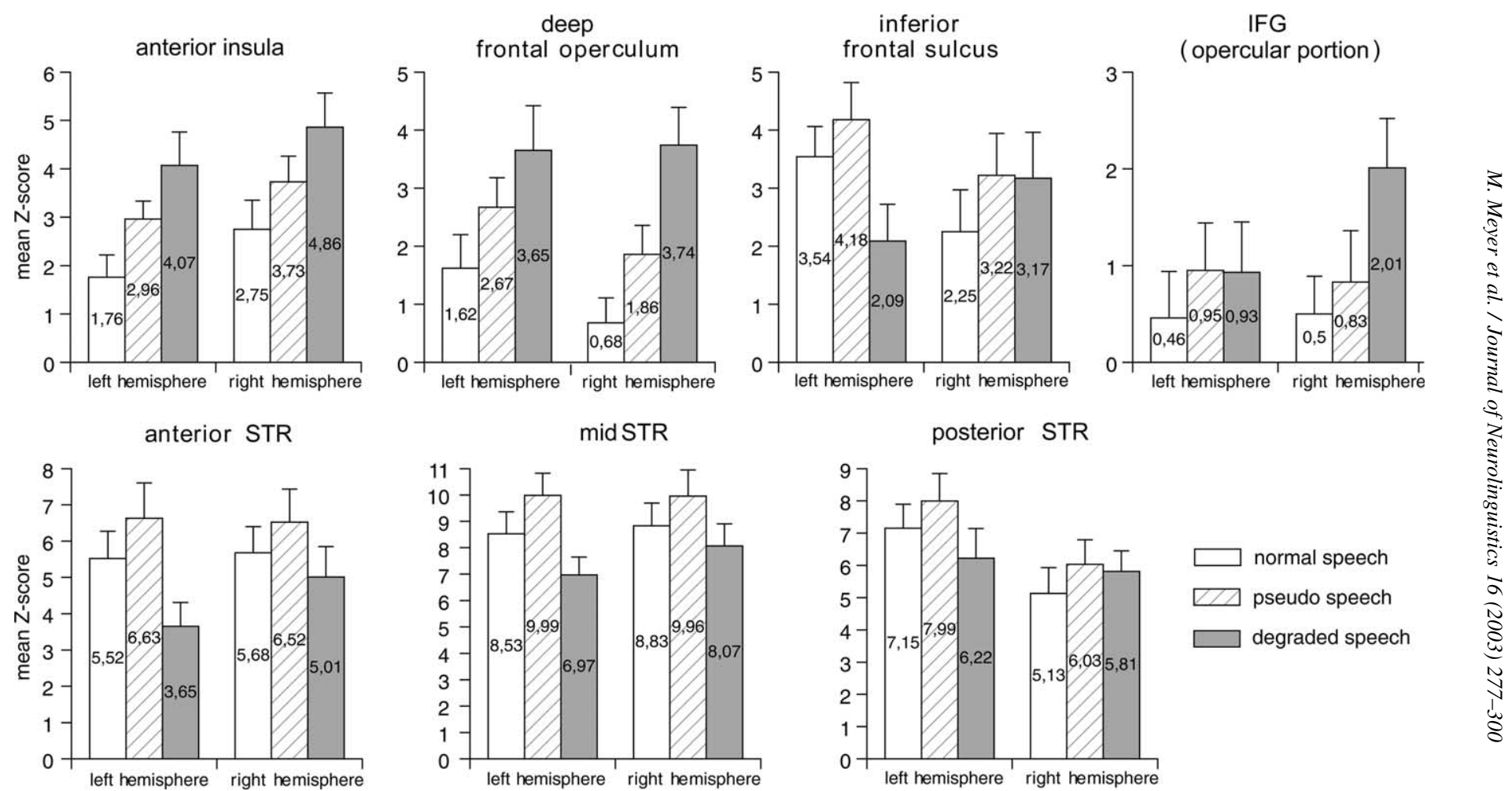

Fig. 5. The figure shows quantified activation (mean $Z$-values) obtained from four frontal (upper row) and three temporal (lower row) bilateral regions of interest (ROIs) separately for normal, pseudo and degraded speech. 
Table 3

Results of a $(2 \times 7 \times 2)$ ANOVA with factors hemisphere $\times$ ROI $\times$ condition for normal and pseudo speech

\begin{tabular}{lccc}
\hline Factor & DF & $F$ value & $P$ value \\
\hline ROI & 6,78 & 39.57 & $P<0.0001$ \\
Hemisphere & 1,13 & 2.29 & $\mathrm{~ns}$ \\
Condition & 1,13 & 64.39 & $P<0.0001$ \\
Hemisphere $\times$ condition & 1,13 & 0.21 & $\mathrm{~ns}$ \\
ROI $\times$ hemisphere & 6,78 & 1.50 & $\mathrm{~ns}$ \\
ROI $\times$ condition & 6,78 & 1.75 & $\mathrm{~ns}$ \\
ROI $\times$ hemisphere $\times$ condition & 6,78 & 0.56 & $\mathrm{~ns}$ \\
\hline
\end{tabular}

conditions across all ROIs were calculated, yielding the new segmental speech condition. Separate $(2 \times 2)$ ANOVAs with factors hemisphere $\times$ condition comparing segmental and degraded speech for each ROI demonstrated significant local changes in signal increase varying as a function of segmentality (Table 4).

Statistical analyses revealed no main effect of hemisphere, but a main effect of condition in each ROI, and an interaction of hemisphere $\times$ condition in each ROI apart from the anterior insula and the primary auditory cortex (Heschl's gyrus) (Table 4). From this observations two conclusions can be drawn: Firstly, degraded speech evoked stronger responses in right inferior fronto-lateral areas lining the ascending ramus of the anterior Sylvian fissure, namely the pars opercularis, the inferior precentral sulcus, and the deep frontal operculum. Secondly, relative to segmental speech containing syntactical and lexical information, degraded speech generally elicited weaker responses in superior

Table 4

Results of a $(2 \times 2)$ ANOVA with factors hemisphere $\times$ condition for segmental speech and degraded speech within each ROI separately

\begin{tabular}{|c|c|c|c|c|}
\hline Region & Factor & DF & $F$ value & $P$ value \\
\hline \multirow[t]{2}{*}{ Anterior insula } & Cond & 1,13 & 12.86 & $P<0.005$ \\
\hline & Cond $\times$ hemi & 1,13 & 0.06 & $\mathrm{~ns}$ \\
\hline \multirow[t]{2}{*}{ Deep frontal operculum } & Cond & 1,13 & 20.35 & $P<0.001$ \\
\hline & Cond $\times$ hemi & 1,13 & 5.88 & $P<0.05$ \\
\hline \multirow[t]{2}{*}{ Inferior pre-central sulcus } & Cond & 1,13 & 5.79 & $P<0.05$ \\
\hline & Cond $\times$ hemi & 1,13 & 13.66 & $P<0.005$ \\
\hline \multirow[t]{2}{*}{ Pars opercularis } & Cond & 1,13 & 13.33 & $P<0.005$ \\
\hline & Cond $\times$ hemi & 1,13 & 9.17 & $P<0.001$ \\
\hline \multirow[t]{2}{*}{ Planum polare } & Cond & 1,13 & 26.13 & $P<0.0005$ \\
\hline & cond $\times$ hemi & 1,13 & 14.50 & $\mathrm{P}<0.005$ \\
\hline \multirow[t]{2}{*}{ Heschl's gyrus } & Cond & 1,13 & 59.24 & $P<0.0001$ \\
\hline & Cond $\times$ hemi & 1,13 & 3.46 & $\mathrm{~ns}$ \\
\hline \multirow[t]{2}{*}{ Planum temporale } & Cond & 1,13 & 4.98 & $P<0.05$ \\
\hline & Cond $\times$ hemi & 1,13 & 6.30 & $P<0.05$ \\
\hline
\end{tabular}


temporal areas, in particular in the left anterior (planum polare) and in the left posterior (planum temporale) superior temporal lobes.

\subsubsection{Discussion}

Activation for pseudo speech relative to normal speech was greater bilaterally in the STR. This finding consistently replicates the activation pattern found in Experiment 1. In terms of pseudo speech all content words were replaced by phonotactically legal pseudowords. Thus, the increase in superior temporal activation may be taken to reflect additional processing when unknown pseudowords are heard and subjects failed to find an equivalent lexical entry. This explanation is also consistent with neuroimaging studies which described a bilaterally distributed neuronal network in the bilateral STR as the substrate of the mental lexicon (Binder, Frost, Hammeke, Rao, \& Cox, 1996; Binder, Rao, \& Hammeke, 1994).

Compared to normal and pseudo speech, activation for degraded speech was generally attenuated in both left and right STR. This finding clearly corroborates our predictions since no segmental, phonemic, lexical, or morphosyntactic information was available in the degraded speech signal. Normal sentence comprehension requires analysis of phonological features of segments, syllables and words, access to the meaning of words, analyses of structural relations between words, and the utilization of prosodic cues to achieve a final interpretation of a spoken utterance. Only the latter operation can be performed in the case of degraded speech. This finding is in harmony with a recent fMRI study that investigated the neural substrates mediating the detection of speech compared with that of nonspeech auditory stimuli (Vouloumanos et al., 2001). In this study, speech stimuli produced stronger activation than nonspeech stimuli in classic receptive language areas in the peri-sylvian cortex bilaterally. Stronger bilateral responses in the supratemporal plane to speech rather than nonspeech vocalizations were also reported by Belin, Zatorre, and Ahad (2002). In particular, our data show that normal and pseudo speech elicited stronger responses in the left anterior (planum polare) and in the left posterior (planum temporale) STR when compared with degraded speech. The anterior segment of the STR has been described as playing a vital role in processing intelligible relative to unintelligible speech (Scott, Blank, Rosen, \& Wise, 2000), (morpho)syntactic information (Friederici, 2002), or combining syntactic and semantic information during sentence comprehension (Kaan \& Swaab, 2002; Stowe et al., 2003). The posterior superior temporal lobe extending into the planum temporale was argued to be involved in early auditory processing common to speech and nonspeech (Binder et al., 2000; Paus, Perry, Zatorre, Worsley, \& Evans, 1996). Jäncke and colleagues recently demonstrated a particular sensitivity of the left planum temporale to phonetic features, namely the voiceonset time (Jäncke, Wüstenberg, Scheich, \& Heinze, 2002). However, according to the authors the left planum temporale is assumed to subserve the analysis of rapidly changing cues rather than phonetic analysis per se which is in agreement with Pöppel's 'asymmetric sampling in time hypothesis' (Pöppel, 2003).

With respect to the frontal cortex the inverse relationship holds: relative to normal and pseudo speech, degraded speech produced strongest frontal activation, in particular in right fronto-lateral areas, namely the inferior precentral sulcus, the deep frontal operculum, and the opercular part of the inferior frontal gyrus. Even though the role of 
right frontal areas in speech processing is still underinvestigated there is converging evidence which associates the right fronto-lateral cortex with the (re-)production of musical and lingual melodies. In detail, the opercular part of the right inferior frontal gyrus has been associated with silent reproduction of auditory presented sentences (Naito et al., 1995), analysis of harmonic sequences (Maess et al., 2001), and rhythmic shaping of speech production (Riecker, Wildgruber, Dogil, Grodd, \& Ackermann, 2002). The caudally adjacent premotor cortex (Rolandic operculum) supports covert speech production and both covert and overt singing (Perry et al., 1999; Riecker, Ackermann, Wildgruber, Dogil, \& Grodd, 2000; Wildgruber, Ackermann, Klose, Kardatzki, \& Grodd, 1996). It might be plausible that in the present study subjects silently reproduced the tune of delexicalized sentence melody in order to accomplish the task instruction. Even though this interpretation is somewhat speculative we draw the conclusion that the right frontolateral activity found in the present study reflects the processing of slow prosodic modulations typically occurring in lingual melodies. In particular, the degraded speech condition utilized in the current study contained prosodic parameters representing intonation contour. Thus, the present fMRI data obtained from normal subjects is in agreement with results from several lesion studies reporting a right hemisphere dominance for the perception and production of intonation contour (Behrens, 1989; Heilman et al., 1984; Schirmer et al., 2001). The present study provides general evidence for the view that intonation might be considered a right hemisphere function, as was previously suggested by a number of lesion studies (Brådvik et al., 1991; Bryan, 1989; Weintraub \& Mesulam, 1981). Additionally, the stronger right temporal sensitivity to pure intonation contour supports the recent model by Pöppel which associates prosody, in particular intonation, with right hemisphere mechanisms (Pöppel, 2003).

The deep frontal operculum and the medially adjacent anterior part of the insula also produced stronger responses to degraded relative to normal and pseudo speech. Even though the anterior insula has been described as supporting speech motor control (Dronkers, 1996), accurate articulation (Wise, Greene, Buechel, \& Scott, 1999), and volational vocalizations (Perry et al., 1999), processing pseudo and degraded speech also recruited the anterior insula and the directly adjacent deep frontal operculum. In both Experiments 1 and 2, brain activation in the fronto-opercular cortex increased with decreasing lexical and morphosyntactic information in the speech signals. Presumably, processing pseudo and degraded speech requires additional computational resources. This observation is consistent with recent fMRI data also demonstrating that speech comprehension and related effort interact in fronto-opercular areas (Giraud et al., 2001) and a PET study that demonstrated an increase in the bifrontal opercular cortex reflecting an increase in processing effort while participants heard musical melodies (Zatorre, Evans, $\&$ Meyer, 1994). Additionally, another recent fMRI study reported increased right inferior cortical responses to incomprehensible relative to comprehensible speech (Poldrack et al., 2001). Thus, the bilateral activation in the fronto-opercular cortex might reflect the effort to achieve a meaningful segmentation of the inflowing auditory input following the extraction of syntactic and lexical-semantic information from pseudo and degraded stimuli, rather than linguistic processes per se.

One might raise the objection that differences in activation between conditions may be confounded by attentional rather than linguistic variables. Given recent fMRI studies that 
attributed attentional mechanisms during auditory speech processing to the bilateral superior temporal cortex (Grady et al., 1997), it is not likely that changes in attentional state modulated brain activation observed in the present study. In using the event-related design which provides a pseudo-randomization of single stimuli, the listener's attention levels should be maintained throughout the entire presentation as there is no reliable way for participants to predict the next stimulus type. At least, it is not reasonable to assume that attention-related changes in brain activation produced an activation increase in FORs, while it is leading to a signal decrease in the STRs simultaneously. Given that degraded speech produced responses at chance-level, one can speculate that subjects did not listen carefully to degraded sentences. However, this objection may not to be plausible because it does not explain why hearing degraded speech corresponds to stronger activation in the FOR than hearing normal and pseudo speech. Even though the fundamental frequency that incorporates pitch information is assumed to be the most critical cue for prosody, we cannot say with confidence that processing the pitch contour purely available in degraded speech accounts for the right fronto-lateral asymmetry in functional brain activation. Finally, we have to consider that besides fundamental frequency, degraded speech also comprises amplitude, duration, and spectral tilt. Further experimental research needs to address the question as to whether individual prosodic cues are operated by different hemispheres (Lakshminarayanan et al., 2003; Pöppel, 2003; Van Lancker \& Sidtis, 1992) and as to what extent each individual parameter shapes the linguistic and emotional interpretation of the received speech (Kotz et al., 2003).

\section{Conclusion}

The data obtained from the two experiments together suggests that normal auditory sentence comprehension occurs automatically, recruiting the STR bilaterally. As hypothesized, no significant activation was found in Broca's area for any sentence condition. This finding indirectly provides evidence for the view that Broca's area is attributed to domain-general rather than to specific linguistic processes (Kaan \& Swaab, 2002; Meyer et al., 2000; Müller et al., 2001; Stowe et al., 2003). However, relative to normal sentences, pseudo speech lacking lexical information, and degraded speech lacking lexical and syntactic information produced stronger activity in deeply buried fronto-opercular cortices which may be explained in terms of effort-related processes. Degraded speech signals, which only comprise prosodic information (sentence melody), to a significant reduction of brain responses in STRs, in particular in the left planum polare and left planum temporale. This finding indirectly demonstrates the critical role the planum polare and the planum temporale play in proper sentence processing. Finally, the data confirmed the view that right hemisphere regions, in particular the right inferior fronto-lateral cortex, respond more sensitively to prosodic information. Taken together, the results obtained from the two experiments suggest a bilateral localization of grammatical and prosodic functions as is also proposed by recent neurocognitive models of speech perception (Friederici, 2002; Pöppel, 2003). 


\section{Acknowledgements}

The authors wish to thank Alice Turk and Adam McNamara for helpful comments on the manuscript. The work was supported by the Leibniz Science Prize awarded to Angela Friederici.

\section{References}

Bavelier, D., Corina, D., Jezzard, P., Padmanabhan, S., Clark, V. P., Karni, A., Prinster, A., Braun, A., Lalwani, A., Rauschecker, J. P., Turner, R., \& Neville, H. (1997). Sentence reading: a functional MRI study at 4 Tesla. Journal of Cognitive Neuroscience, 9, 664-686.

Behrens, S. (1989). Characterizing sentence intonation in a right-hemisphere damaged population. Brain and Language, 37, 181-200.

Belin, P., Zatorre, R. J., \& Ahad, P. (2002). Human temporal-lobe response to vocal sounds. Cognitive Brain Research, 13, 17-26.

Binder, J. R., Frost, J. A., Hammeke, T. A., Bellgowan, P. S. F., Springer, J. A., Kaufman, J. N., \& Possing, E. T. (2000). Human temporal lobe activation by speech and nonspeech sounds. Cerebral Cortex, 10, 512-528.

Binder, J. R., Frost, J. A., Hammeke, T. A., Rao, S. M., \& Cox, R. W. (1996). Function of the left planum temporale in auditory and linguistic processing. Brain, 119, 1239-1254.

Binder, J. R., Rao, S. M., \& Hammeke, T. A. (1994). Functional magnetic resonance imaging of human auditory cortex. Annals of Neurology, 35, 662-672.

Binkofski, F., Amunts, K., Stephan, K. M., Posse, S., Schormann, T., Freund, H. J., Zilles, K., \& Seitz, R. J. (2000). Broca's region subserves imagery of motion: a combined cytoarchitectonic and fMRI-study. Human Brain Mapping, 11, 273-285.

Blumstein, S., \& Cooper, W. E. (1974). Hemispheric processing of intonation contours. Cortex, 10, $147-158$.

Bogen, J. E., \& Bogen, G. M. (1976). Wernicke's region-Where is it? Annals of the New York Academy of Sciences, 280, 834-843.

Bosch, V. (2000). Statistical analysis of multi-subject fMRI data: the assessment of focal activations. Journal of Magnetic Resonance Imaging, 11, 61-64.

Bottini, G., Corcoran, R., Sterzi, R., Paulesu, E., Schenone, P., Scarpa, P., Frackowiak, R., \& Frith, C. (1994). The role of right hemisphere in interpretation of figurative aspects of language. A positron emission tomography activation study. Brain, 117, 1241-1253.

Brådvik, B., Dravins, C., Holtas, S., Rosen, I., Ryding, E., \& Ingvar, D. (1991). Disturbances of speech prosody following right hemisphere infarcts. Acta Neurologica Scandinavia, 84, 114-126.

Bryan, K. (1989). Language prosody in the right hemisphere. Aphasiology, 3, 285-299.

Burton, M. W. (2001). The role of inferior frontal cortex in phonological processing. Cognitive Science, 25, 695-709.

Burton, M. W., Small, S. L., \& Blumstein, S. E. (2000). The role of segmentation in phonological processing: an fMRI investigation. Journal of Cognitive Neuroscience, 12, 679-690.

Caplan, D., Alpert, N., \& Waters, G. (1998). Effects of syntactic structure and propositional number on patterns of regional cerebral blood flow. Journal of Cognitive Neuroscience, 10, 541-552.

Caplan, D., Alpert, N., \& Waters, G. (1999). PET studies of syntactic processing with auditory sentence presentation. NeuroImage, 9, 343-351.

Caplan, D., Alpert, N., Waters, G., \& Olivieri, A. (2000). Activation of Broca's area by syntactic processing under conditions of concurrent articulation. Human Brain Mapping, 9, 65-71.

Caplan, R., \& Dapretto, M. (2001). Making sense during conversation: an fMRI study. NeuroReport, 12, 3625-3632.

Caplan, D., Hildebrandt, N., \& Makris, N. (1996). Location of lesions in stroke patients with deficits in syntactic processing in sentence comprehension. Brain, 119, 933-949. 
Carpentier, A., Pugh, K. R., Westerveld, M., Studholme, C., Skrinjar, O., Thompson, J. L., Spencer, D. D., \& Constable, R. T. (2001). Functional MRI of language processing: dependence on input modality and temporal lobe epilepsy. Epilepsia, 42, 1241-1254.

Carramazza, A., \& Zurif, E. B. (1976). Dissociation of algorithmic and heuristic processes in language comprehension: evidence from aphasia. Brain and Language, 3, 572-582.

Cooke, A., Zurif, E. B., DeVita, C., Alsop, D., König, P., Detre, J., Gee, J., Pinango, M., Balogh, J., \& Grossman, M. (2002). Neural basis for sentence comprehension: grammatical and short-term memory components. Human Brain Mapping, 15, 80-94.

Corina, D., Vaid, J., \& Bellugi, U. (1992). The linguistic basis of left hemisphere specialization. Science, 255, $1258-1260$.

Dapretto, M., \& Bookheimer, S. Y. (1999). Form and content: dissociating syntax and semantics in sentence comprehension. Neuron, 24, 427-432.

D’Esposito, M., Zarahn, E., \& Aguirre, G. K. (1999). Event-related functional MRI: implications for cognitive psychology. Psychological Bulletin, 125, 155-164.

Dronkers, N. (1996). A new brain region for coordinating speech articulation. Nature, 384, 159-161.

Dronkers, N. F., Redfern, B. B., \& Knight, R. T. (1999). The neural architectures of language disorders. In M. A Gazzaniga (Ed.), The new cognitive neuroscience (pp. 949-958). Cambridge, MA: MIT Press.

Dronkers, N., Shapiro, J. K., Redfern, B., \& Knight, R. T. (1992). The third left frontal convolution and aphasia: On beyond Broca. Journal of Clinical and Experimental Neuropsychology, 14, 52-53.

Dronkers, N., Wilkins, D. P., Van Vilin, R. D., Redfern, B. B., \& Jaeger, J. J. (1994). A reconsideration of the brain areas involved in the disruption of morphosyntactic comprehension. Brain and Language, 47, 461-463.

Embick, D., Marantz, A., Miyashita, Y., O’Neil, W., \& Sakai, K. L. (2000). A syntactic specialization for Broca's area. Proceedings of the National Academy of Sciences of the United States of America, 97, 6150-6154.

Fiebach, C., Schlesewsky, M., \& Friederici, A. (2001). Syntactic working memory and the establishment of fillergap dependencies: insight from ERPs and fMRI. Journal of Psycholinguistic Research, 30, 321-338.

Friederici, A. D. (2002). Towards a neural basis of auditory sentence processing. Trends in Cognitive Science, 6 , $78-84$.

Friederici, A. D., Meyer, M., \& von Cramon, D. Y. (2000a). Auditory language comprehension: an event-related fMRI study on the processing of syntactic and lexical information. Brain and Language, 75, 465-477.

Friederici, A. D., Wang, Y., Herrmann, C. S., Maess, B., \& Oertel, U. (2000b). Localization for early synaptic processes in frontal and temporal cortical areas: a magnet encephalographic study. Human Brain Mapping, $11,1-11$

Friston, K. J., Price, C. J., Fletcher, P., Moore, C., Frackowiak, R. S. J., \& Dolan, R. J. (1996). The trouble with cognitive subtraction. NeuroImage, 4, 97-104.

Giraud, A. L., Kell, C., Klinke, R., Russ, M. O., Sterzer, P., Thierfelder, C., Preibisch, C., \& Kleinschmidt, A (2001). Dissociating effort and success in speech comprehension: an fMRI study. NeuroImage, 13, S534.

Goodglass, H. (1993). Understanding aphasia. San Diego: Academic Press.

Grady, C. L., Van Meter, J. W., Maisog, J. M., Pietrini, P., Krasuski, J., \& Rauschecker, J. P. (1997). Attentionrelated modulation of activity in primary and secondary auditory cortex. Neuro Report, 8, 2511-2516.

Grodzinsky, Y. (2000). The neurology of syntax: language use without Broca's area. Behavioural Brain Science, $23,1-71$

Heilman, K. M., Bowers, D., Speedie, L., \& Coslett, H. B. (1984). Comprehension of affective and nonaffective prosody. Neurology, 84, 917-921.

Hickok, G., \& Pöppel, D. (2000). Towards a functional neuroanatomy of speech perception. Trends in Cognitive Science, 4, 131-138.

Humphries, C., Buchsbaum, C., \& Hickok, G. (2001). Role of anterior temporal cortex in auditory sentence comprehension: an fMRI study. NeuroReport, 12, 1749-1752.

Indefrey, P., Hagoort, P., Herzog, H., Seitz, R. J., \& Brown, C. M. (2001). Syntactic processing in left prefrontal cortex is independent of lexical meaning. NeuroImage, 14, 546-555.

Inui, T., Otsu, Y., Tanaka, S., Okada, T., Nishizawa, S., \& Konishi, J. (1998). A functional MRI analysis of comprehension processes of Japanese sentences. NeuroReport, 9, 3325-3328.

Jäncke, L., Wüstenberg, T., Scheich, H., \& Heinze, H. (2002). Phonetic perception and the temporal cortex. NeuroImage, 15, 733-746. 
Just, M. A., Carpenter, P. A., Keller, T. A., Eddy, W. F., \& Thulborn, K. R. (1996). Brain activation modulated by sentence comprehension. Science, 274, 114-116.

Kaan, E., \& Swaab, T. Y. (2002). The brain circuitry of syntactic comprehension. Trends in Cognitive Science, 6 , $350-356$.

Kang, A. M., Constable, R. T., Gore, J. C., \& Avrutin, S. (1999). An event-related fMRI study of implicit phraselevel syntactic and semantic processing. NeuroImage, 9, 555-561.

Keller, T. A., Caplan, D., \& Waters, G. (2001). The neural bases of sentence comprehension: a fMRI examination of syntactic and lexical processing. Cerebral Cortex, 11, 223-237.

Kotz, S. A., Meyer, M., Alter, K., Besson, M., von Cramon, D. Y., \& Friederici, A. D. (2003). On the lateralization of emotional prosody: an event-related functional MR investigation. Brain and Language, in press, doi 10.1016/S0093-934X(02)00532-1.

Kruggel, F., \& Lohmann, G. (1996). BRIAN (Brain Image Analysis): A toolkit for the analysis of multimodal brain datasets. In H. U. Lemke, M. W. Vannier, K. Inamura, \& A. G. Farman (Eds.), CAR'96 Computer Assisted Radiology, Paris 1996 (pp. 323-328). Amsterdam: Elsevier.

Lakshminarayanan, K., Shalom, D., van Wassenhove, V., Orbelo, D., Houde, J., \& Pöppel, D. (2003). The effect of spectral manipulation on the identification of affective and linguistic prosody. Brain and Language, 84, $250-263$.

Levelt, W. M. J. (2000). The brain does not serve linguistic theory so easily. Behavioral and Brain Science, 23, 40-41.

Linebarger, M. C., Schwartz, M. F., \& Saffran, E. M. (1983). Sensitivity to grammatical structure in so-called agrammatic aphasics. Cognition, 7, 433-485.

Lohmann, G., Müller, K., Bosch, V., Mentzel, H., Hessler, S., Chen, L., Zysset, S., \& von Cramon, D. Y. (2001). Lipsia: a new software system for the evaluation of functional magnetic resonance images of the human brain. Computerized Medical Imaging and Graphics, 25, 449-457.

Maess, B., Kölsch, S., Gunter, T. C., \& Friederici, A. D. (2001). Musical syntax is processed in Broca's area: an MEG study. Nature Neuroscience, 4, 540-545.

Mazoyer, B. M., Tzourio, N., Frak, V., Syrota, A., Murayama, N., Levrier, O., Salamon, G., Dehaene, S., Cohen, L., \& Mehler, J. (1993). The cortical representation of speech. Journal of Cognitive Neuroscience, 5, 467-479.

Meyer, M., Friederici, A. D., \& von Cramon, D. Y. (2000). Neurocognition of auditory sentence comprehension: event-related fMRI reveals sensitivity to syntactic violations and task demands. Cognitive Brain Research, 9 , $19-33$.

Mohr, J. P., Pessin, M. S., Finkelstein, S., Funkenstein, H. H., Duncan, G. W., \& Davis, M. D. (1978). Broca aphasia: pathologic and clinical. Neurology, 28, 311-324.

Morosan, P., Rademacher, J., Schleicher, A., Amunts, K., Schormann, T., \& Zilles, K. (2001). Human primary auditory cortex: cytoarchitectonic subdivisions and mapping into a spatial reference system. NeuroImage, 13, 684-701.

Müller, R.-A., Kleinhans, N., \& Courchesne, E. (2001). Broca's area and the discrimination of frequency transitions: a functional MRI study. Brain and Language, 76, 70-76.

Müller, R.-A., Kleinhans, N., Pierce, K., Kemmotsu, N., Courchesne, E., \& Functional, M. R. I. (2002). of motor sequence acquisition: effects of learning stage and performance. Cognitive Brain Research, 14, $277-293$.

Müller, R.-A., Rothermel, R. D., Behen, M. E., Muzik, O., Mangner, T. J., \& Chugani, H. T. (1997). Receptive and expressive language activations for sentences: a PET study. NeuroReport, 8, 3767-3770.

Naito, Y., Okazawa, H., Honjo, I., Hirano, S., Takahashi, H., Shiomi, Y., Hoji, W., Kawano, M., Ishizu, K., \& Yonekura, Y. (1995). Cortical activation with sound stimulation in cochlear implant users demonstrated by positron emission tomography. Cognitive Brain Research, 2, 207-214.

Newman, A. J., Pancheva, R., Ozawa, K., Neville, H. J., \& Ullman, M. T. (2001). An event-related fMRI study of syntactic and semantic violations. Journal of Psycholinguistic Research, 30, 339-364.

Ni, W., Constable, R. T., Mencl, W. E., Pugh, K. R., Fulbright, R. K., Shaywitz, S. E., Shaywitz, B. A., Gore, J. C., \& Shankweiler, D. (2000). An event-related neuroimaging study distinguishing form and content in sentence processing. Journal of Cognitive Neuroscience, 12, 120-133.

Norris, D. G. (2000). Reduced power multi-slice MDEFT imaging. Magnetic Resonance Imaging, 11, 445-451. 
Paus, T., Perry, D. W., Zatorre, R. J., Worsley, K. J., \& Evans, A. C. (1996). Modulation of cerebral blood flow in human auditory cortex during speech: role of motor-to-sensory discharges. European Journal of Neuroscience, 8, 2236-2246.

Perkins, J. M., Baran, J. A., \& Gandour, J. (1996). Hemispheric specialization in processing intonation contours. Aphasiology, 10, 343-362.

Perry, D. W., Zatorre, R. J., Petrides, M., Alivisatos, B., Meyer, E., \& Evans, A. C. (1999). Localization of cerebral activity during simple singing. NeuroReport, 11, 3979-3984.

Poldrack, R. A., Temple, E., Protopapas, A., Nagarajan, S., Tallal, P., Merzenich, M., \& Gabrieli, J. D. E. (2001). Relations between the neural bases of dynamic auditory processing and phonological processing: evidence from fMRI. Journal of Cognitive Neuroscience, 13, 687-697.

Poldrack, R. A., Wagner, A. D., Prull, M. W., Desmond, J. E., Glover, G. H., \& Gabrieli, J. D. E. (1999), Functional specialization for semantic and phonological processing in the left inferior prefrontal cortex. NeuroImage, 10, 15-35.

Pöppel, D. (1996). A critical review of PET studies of phonological processing. Brain and Language, 55, 317-351.

Pöppel, D. (2003). The analysis of speech in different temporal integration windows: cerebral lateralization as 'asymmetric sampling in time'. Speech and Communication, in press, doi 10.1016/S0167-6393(02)00107-3.

Price, C. J., Wise, R., \& Frackowiak, R. S. J. (1996). Demonstrating the implicit processing of visually words and pseudowords. Cerebral Cortex, 6, 62-70.

Riecker, A., Ackermann, H., Wildgruber, D., Dogil, G., \& Grodd, W. (2000). Opposite hemispheric lateralization effects during speaking and singing at motor cortex, insula and cerebellum. NeuroReport, 11, 1997-2000.

Riecker, A., Wildgruber, D., Dogil, G., Grodd, W., \& Ackermann, H. (2002). Hemispheric lateralization effects of rhythm implementation during syllable repetitions: an fMRI study. NeuroImage, 16, 169-176.

Rosen, B. R., Buckner, R. L., \& Dale, A. M. (1998). Event-related functional MRI: past, present and future. Proceedings of the National Academy of Sciences of the United States of America, 95, 773-780.

Sakai, K. L., Hashimoto, R., \& Homae, F. (2001). Sentence processing in the cerebral cortex. Neuroscience Research, 39, 1-10.

Schirmer, A., Alter, K., Kotz, S. A., \& Friederici, A. D. (2001). Lateralization of prosody during language production: a lesion study. Brain and Language, 76, 1-17.

Schlosser, M. J., Aoyagi, N., Fulbright, R. K., Gore, J. C., \& McCarthy, G. (1998). Functional MRI studies of auditory comprehension. Human Brain Mapping, 6, 1-13.

Schubotz, R. I., \& von Cramon, D. Y. (2001). Interval and ordinal properties of sequences are associated with distinct premotor areas. Cerebral Cortex, 11, 210-222.

Scott, S. K., Blank, C. C., Rosen, S., \& Wise, R. J. S. (2000). Identification of a pathway for intelligible speech in the left temporal lobe. Brain, 123, 2400-2406.

Shattuck-Hufnagel, S., \& Turk, A. E. (1996). A prosody tutorial for investigators of auditory sentence processing. Journal of Psycholinguistic Research, 25, 193-247.

Sonntag, G. P., \& Portele, T. (1998). PURR: a method for prosody evaluation and investigation. Journal of Computer Speech and Language, 12, 437-451.

St. George, M., Kutas, M., Martinez, A., \& Sereno, M. I. (1999). Semantic integration in reading: engagement of the right hemisphere during discourse processing. Brain, 122, 1317-1325.

Stowe, L., Cees, A., Broere, A., Paans, A., Wijers, A., Mulder, G., Vaalburg, W., \& Zwarts, F. (1998) Localizing components of a complex task: sentence processing and working memory. NeuroReport, 9, 2995-2999.

Stowe, L. A., Haverkort, M., \& Zwarts, F (2003). Rethinking the neurological basis of language. Submitted for publication.

Stromswold, K., Caplan, D., Alpert, N., \& Rauch, S. (1996). Localization of syntactic comprehension by positron emission tomography. Brain and Language, 52, 452-473.

Talairach, J., \& Tournoux, P. (1988). Co-planar stereotaxic atlas of the human brain. New York: Thieme.

Ugurbil, K., Garwood, M., Ellermann, J., Hendrich, K., Hinke, R., Hu, X., Kim, S.-G., Menon, R., Merkle, H., \& Ogawa, S. R. S. (1993). Magnetic fields: initial experiences at 4 T. Magnetic Resonance Quarterly, 9, 259. 
Vandenberghe, R., Nobre, A. C., \& Price, C. J. (2002). The response of left temporal cortex to sentences. Journal of Cognitive Neuroscience, 14, 550-560.

Van Lancker, D., \& Sidtis, J. J. (1992). The identification of affective-prosodic stimuli by left- and right hemisphere-damaged subjects: all errors are not created equal. Journal of Speech and Hearing Research, 35, 963-970.

Vouloumanos, A., Kiehl, K., Werker, J. F., \& Liddle, P. F. (2001). Detection of sounds in the auditory stream: event-related fMRI evidence for differential activation to speech and nonspeech. Journal of Cognitive Neuroscience, 13, 994-1005.

Weintraub, S., \& Mesulam, M.-M. (1981). Disturbances of prosody. A right-hemisphere contribution to language. Archives of Neurology, 38, 742-744.

Wildgruber, D., Ackermann, H., Klose, U., Kardatzki, B., \& Grodd, W. (1996). Functional lateralization of speech production at primary motor cortex: a fMRI study. NeuroReport, 7, 2791-2795.

Wise, R. J. S., Greene, J., Buchel, C., \& Scott, S. K. (1999). Brain regions involved in articulation. The Lancet, $353,1057-1061$.

Zaidel, D. W., Zaidel, E., Oxbury, S. M., \& Oxbury, J. M. (1995). The interpretation of sentence ambiguity in patients with unilateral focal brain surgery. Brain and Language, 51, 458-468.

Zarahn, E., Aguirre, G., \& D’Esposito, M. (1997). A trial-based experimental design for fMRI. NeuroImage, 6, $122-138$.

Zatorre, R. J., Evans, A. C., \& Meyer, E. (1994). Neural mechanisms underlying melodic perception and memory for pitch. The Journal of Neuroscience, 14, 1908-1919. 